\title{
El sapo homosexual de Nestor Vítor (1897)
}

\author{
César Braga-Pinto \\ Northwestern University
}

Si bien es cierto que, en las mitologías clásicas y medievales, alguna vez los batracios disfrutaron de algún privilegio al estar comúnmente asociados con lo mágico y lo misterioso, la modernidad no ha sido tan generosa con ellos ${ }^{1}$. En su Historia Natural (1749-1804), Buffon los describe como "seres indignos", "condenados a la desgracia, con sus malos hábitos, cualidades asquerosas y rasgos peligrosos". Según el naturalista francés, "todo en ellos es villanía, incluso su nombre, que se ha convertido en sinónimo de una profunda deformidad" (p. 247). No es sorprendente, por tanto, que, en su condición de ser inferior, la imagen del sapo vuelva a ocupar un lugar especial en la poética simbolista, especialmente cuando se desarrolla el interés moderno por lo feo, por un lado, y por la figura marginal, por el otro. De hecho, desde Víctor Hugo ("Le Crapaud", 1858) y más allá de Paul Verlaine, la poesía francesa está poblada de crapauds². Pero fue con Tristan Corbière quien, según sus biógrafos, fue víctima de algún tipo de reumatismo que lo habría desfigurado y murió de tuberculosis a los 29 años, que el animal se asoció más explícitamente con el poète maudit. De hecho, su poema célebre, "Le Crapaud" (1873), describe al sapo como poète tendu, sans aile / Rossignol de la boue ... Horreur! y termina con una identificación completa entre el yo-poeta y el sapo en el pantano: Bonsoir - ce crapaud-là c'est moi (Corbière) ${ }^{3}$. Asimismo, también en la escultura, el francés Jean-Joseph Carriès (1855-1894) haría del hombre-sapo el objeto de una de sus principales obras, Le Grenouillard (1892).

En Brasil, los sapos han encontrado un hábitat particularmente acogedor en la poética de los simbolistas y decadentistas, desde la traducción del poema de Corbière por Pedro Kilkerry (1885-1917) (Muricy, p. 876) hasta el nombre de una de las revistas literarias más importantes del movimiento: O Sapo: Semanário Literário e Humorístico (Curitiba, 1898). Es correcto afirmar que hoy la mayor parte de esos poetas-batracios de renombre en su momento permanece oculta o ha sido olvidada en la penumbra de los manuales de historia literaria. Pero la predilección, la obsesión con el tema, el que era recitado tanto en prosa como en verso, no deja de ser digna de mención: Luiz

\footnotetext{
1 Según Simon Goldhill, los sapos eran asociados con magos y venenos, pero también traían una sensación de esperanza y de cura, como lo demuestra la máxima de Shakespeare: Sweet are the uses of adversity, which like the toad, ugly and venomous, wears yet a precious jewel in his head ("Dulces son los usos de la adversidad que, como el sapo, feo y venenoso, aun llevan en la cabeza una joya preciosa") (Shakespeare apud Goldhill, 2011). 2 Verlaine es autor de "Lourd comme un crapaud, léger comme un oiseau", Epigrammes, 1894; Octave Mirabeau escribió "Le Crapaud" (Lettres de ma chaumière, A. Laurent, 1886, pp. 135-50) y Jean Lorrain tiene un texto en prosa con el mismo título ("Le Crapaud", 1895 em Sensations et Souvenir. Paris: Bibliothèque-Charpentier).

3 Corbière escribió también en "Paysage Mauvais": "Les crapauds / Petits chantres mélancoliques/ Empoisonnent de leurs coliques,/ Les champignons, leurs escabeaux...".
} 
Cardozo ("O Sapo e o Homem", 1880); Alves de Faria ("Batráquio", 1897,), Antônio Austragésilo ("O Sapo", 1898), Pereira da Silva ("O Sapo", 1901), Euclides Bandeira ("O Sapo", 1903), Gonzaga Duque ("Sapo!", 1914), da Costa e Silva ("O Sapo", 1917), Faria Neves Sobrinho ("O Pântano", 1920), Mário José de Almeida ("Poema dos Sapos", 1920), Cruz Filho ("A Ilusão do Sapo", 1924), entre otros, todos escribieron poemas o prosa poética sobre sapos, pantanos y lagunas.

Pero fue João da Cruz e Sousa (1861-1898) quien por primera vez trajo la figura del sapo hacia el centro de la poética simbolista y finisecular. Ya en uno de sus primeros poemas (de 1885), el poeta identificaba, un tanto paradójicamente, los horrores de la esclavitud en la imagen del "sapo negro", emblema de todo lo que es horrendo o abyecto:

\author{
Levantem esta bandeira \\ Da posição de farrapo; \\ Da terra azul brasileira \\ Levantem esta bandeira \\ Que sente o horror da esterqueira \\ Da escravidão - negro sapo. \\ Levantem esta bandeira \\ Da posição de farrapo. \\ Cruz e Sousa (2000, p. 342)
}

Más tarde, en un poema de Missal, de 1893, la corporización de lo Feo, entre la imagen del simio y del batracio, remite al spleen y a los albatros de Baudelaire $y$, en lugar de objeto de horror, representa una nueva estética y nuevas artísticas sensibilidades nervosas, vibráteis, quase feminis (Cruz e Sousa, p. 474). Es decir, el poeta decadentista ahora se siente atraído o simpatiza con todo lo que es horrendo y poco convencional, con el Otro, con lo Feo, que es objeto de prejuicio y de desprecio de los contemporáneos: Às vezes uma gesticulação epilética, nevrótica, clownesca, faz impetuosa botar a gargalhada das turbas, enquanto tua voz coaxa e grasna [...] (Cruz e Sousa, p. 473). Además, el signo de lo abyecto se convierte en un ejemplo de integridad y rectitud: Conquanto tenhas também, na tua hediondez, toda a correção perfeita - como o sapo, coaxando cá embaixo na lodosa argila, tem, no entanto, a repelente cor- reção própria de sapo. Al mismo tiempo, la elección del poeta que adora lo Feo no deja de representar una fatalidad inevitable, la condena de aquel cuya fascinación por lo abyecto no es más que la expresión patológica de su más profunda melancolía: Esta extravagante, excêntrica, singular influência mórbida que nas funções de meu cérebro vem, contudo, como doença amarga... (Cruz e Sousa, p. 475).

Esta misma oscilación entre el sentimiento de encarnar un elegido y representar la abyección, entre la redención y la condena, se expresa en otro poema de Cruz e Sousa, el muy conocido "Sapo humano", en el que el animal deja de ser simplemente una abstracción para convertirse en el retrato del

4 Publicado originalmente en $O$ moleque, 31 de mayo de 1885. 
sujeto despreciado injustamente por la sociedad y que, sin embargo, resiste y anhela la redención por medio del amor:

Mas és o sapo humano, o sapo mais abjeto

Do crime aterrador, do tenebroso vício

Mas que ainda possuis o brilho de um afeto

Que te livra, talvez, do eterno precipício.

(Cruz e Sousa, pp. 397-8)

Cruz e Sousa (el poeta y la poesía) se inserta en aquel linaje que abarca desde los primeros románticos, los miserables, los infelices y los tuberculosos (como él mismo terminaría sus días) hasta el poeta maldito y el decadente del fin-de-siècle. Pero, a pesar del supuesto aislamiento y reclusión al que es condenado el genio del poeta, enemigo de la sociedad burguesa y de la convención, ese "mito da maldição literária" (Brissette. s.p.), no deja de ser también una promesa de comunidad. Ya en Stello (1832), del romántico Alfred de Vigny, quien consagra la imagen del poeta infeliz y moribundo y prototipo del poeta maldito finisecular, la maldición aparece no solo como el destino de un individuo, sino también como la fatalidad de una casta victimizada por la opinión de los poderosos que encuentra en la literatura su salvación y su condena: "Desde el día en que aprendió a leer, ha sido un Poeta, y desde entonces ha pertenecido a la raza siempre maldecida por los poderes de la tierra" (Vigny, 1832, cap. XII, s.p., traducción nuestra). O incluso, cuando en la misma obra del escritor francés, se cita la carta de un joven poeta inglés que lamenta:

¿Por qué me criaron como soy? Hice lo que debería haber hecho, y los hombres me rechazaron como a un enemigo. Si en la multitud no hay lugar para mí, me voy [...] iOh dulce e inocente Kitty Bell! ¿Sabes que existe una raza de hombres con corazones secos y ojos microscópicos, armados con pinzas y garras? Este hormiguero se extiende, rueda, se precipita sobre los libros, roe, hiere, rasga, cala más de prisa y más profundo que el gusano enemigo de las bibliotecas. Ninguna emoción mueve a esa familia imperecedera, ninguna inspiración la eleva, ninguna luz la anima o la enardece; esta raza indestructible y destructiva, cuya sangre es fría como la de una víbora o la de un sapo, ve claramente las tres manchas del sol, y jamás reparó en sus rayos (Vigny, 1832, cap. XV, s.p., traducción nuestra).

Enemigo de sus enemigos, el poeta busca en la poesía el refugio de los exiliados. Como sugiere Pascal Brissette, al ser reescrito y vivido por el poeta de la segunda mitad del siglo XIX, el "mito de la maldición literaria", previamente mencionado por una tradición de discursos en la que se traza la conexión entre el infortunio (la enfermedad, la miseria, la persecución) y, al mismo tiempo, su valorización (la sabiduría, la virtud, la sensibilidad), resurge como la historia ejemplar del escritor cuyo genio lo lleva a la infelicidad o, por el contrario, descubre su genio mediante la propia enfermedad y del sufrimiento (Brissette § 34, sp). 
El poeta maldito (consagrado por Verlaine en 1884, con la colección Les Poètes Maudits) en la obra de Cruz e Sousa difícilmente podría disociarse el tema de la raza proscrita y del destino trágico del negro, aunque la cuestión racial sea apenas ocasionalmente abordada. Así, en su poesía, las abstracciones simbolistas a menudo se confunden con las imágenes típicas del naturalismo, con su estigmatización del cuerpo negro y las subjetividades no normativas. La poesía le sirve al poeta simbolista negro, en la posición de sujeto y objeto del naturalista, de arma contra las doctrinas positivistas de la evolución y del progreso. Porque, como señala Alfredo Bosi en su lectura de "O Emparedado", se combinan y se tropicalizan allí las imágenes del poeta maldito, por un lado, y de la raza condenada de Cam, por el otro. De hecho, es en su prosa poética donde Cruz e Sousa protesta con más contundencia contra el estigma del poeta negro, cuyo "crimen infame" consiste solo en osar levantarse por encima del espacio a él designado por las normas sociales del blanco:

Foi bastante pairar mais alto, na obscuridade tranquila, na consoladora e doce paragem das Ideias, acima das graves letras maiúsculas da Convenção, para alvoroçarem-se os Preceitos, irritarem-se as Regras, as Doutrinas, as Teorias, os Esquemas, os Dogmas, armados e ferozes, de cataduras hostis e severas (Cruz e Sousa, p. 661).

Y más adelante, agrega el poeta, ironizando contra las acusaciones del adversario hostil que hizo del negro un enemigo: Tu és dos de Cam, maldito, réprobo, anatematizado! Falas em Abstrações, em formas, em Espiritualidades, em Requintes, em Sonhos! Como se tu fosses das raças de ouro e da aurora, se viesses dos arianos [...] (p. 672). Ya Roger Bastide había asociado las dos maldiciones, pero atribuye esa identidad a un deseo de blanqueamiento: Metamorfoseou assim o seu protesto racial em uma revolta estética, seu isolamento étnico em isolamento de poeta [...] transformando a maldição racial em maldição universal, passava a linha de cor com sua própria dor, fazendo dela uma dor ocidental, uma dor europeia (Bastide, p. 108). Bosi demuestra cómo la retórica del poeta maldito en Cruz e Sousa se traduce al lenguaje del estigma racial, asumiendo un aspecto, al mismo tiempo, individual y colectivo: Fazendo a alma de Baudelaire nascer dentro de um sol africano, Cruz e Sousa superpôs as duas dimensões do poeta maldito (Bosi, p. 182). Así, el crítico concluye:

O maldito será, portanto, ora o poeta hostilizado mas indomável [...] ora um temperamento fatalizado pelo sangue, o que é o destino do negro que traria no corpo os desejos e os estigmas do continente anatematizado. Adotando o vocabulário naturalista ao falar em temperamento fatalizado pelo sangue, Cruz e Sousa assimilou paradoxalmente a linguagem do determinismo racial contra a qual se insurgia (p. 179).

En otras palabras, el motivo de la maldición que tornaba al poeta europeo en un elegido, se literaliza en la expresión del simbolista negro, que vive la maldición en su propia piel. Asimismo, la hostilidad de los representantes 
de la norma (social, racial y, como veremos más adelante, sexual) nunca podrá disociarse por completo de la violencia cotidiana y de los prejuicios y, específicamente, de las instancias de violencia lingüística, de los insultos, de las injurias y de la humillación pública contra el poeta que siempre permanecerá en la condición de maldito (Eles riem, eles riem e eu caminho e sonho tranquilo! (Cruz e Sousa, p. 667). Es que en el Río de Janeiro finisecular, el negro es sin duda el más visible y el más vulnerable de todos los marginados, marcado por el estigma, o por lo que Cruz e Sousa llamará, en otro gesto universalizador, una "mancha": estranha nódoa que, no entanto, sem que ele soubesse ou pudesse determinar nitidamente no cérebro alucinado, era a profunda, a incoercível, a grande nódoa negra simbólica da sua própria vida (p. 615).

No siendo el estigma puramente físico, y nunca librada de su potencial de abstracción, la figura de la maldición se presta y se aplica también a la representación de otras estigmatizaciones y exclusiones sociales, incluidos la condición y el destino de los disidentes sexuales. Así, en 1897, solo dos años después de que el naturalismo hubiera patologizado al homosexual negro en las páginas de Bom-Crioulo (1895) de Adolfo Caminha, Cruz e Sousa escribe un largo ensayo en Signos, el volumen recientemente publicado de cuentos de Nestor Vítor, su amigo íntimo y protector. En el núcleo estructural del libro, el poeta se centra en "Sapo", un cuento fantástico que trata explícitamente de la homosexualidad. A pesar del léxico grandilocuente (el dolor, la vida, el sueño, lo real, la incorruptibilidad, la transparencia, etc.), poco atractivo al gusto contemporáneo, esa narrativa urbana, hoy prácticamente olvidada en el archivo simbolista, no solo parece radical para su época, pero también hace eco de las narraciones queer escritas casi un siglo después (como, por ejemplo, el cuento "Aqueles Dois" de Caio Fernando Abreu) 5 .

"Sapo" aborda el fin de lo que el crítico Massaud Moisés llama una "amistad medio extraña" (Moisés, p. 238) entre dos hombres, planteando, sin mayores rodeos, los deseos homosexuales de los personajes, la vulnerabilidad del cuerpo disidente y el poder injurioso del lenguaje. El cuento comienza con una riña entre dos colegas en la oficina de una fábrica: Ernesto, joven de 24 años, y su amigo Bruce, de 30 años, hijo de un inmigrante irlandés. El motivo (shakesperiano / lombrosiano) de la pelea son los celos incontrolables (¿enfermos?) de Bruce, su sentido de traición causado por el hecho de que su compañero inseparable había comenzado una relación con una mujer a la que él consideraba indigna, uma farpelha, rameira: Aquela mulher se the tornara uma espécie de rival, uma concorrente insuportável que Ihe andava pleiteando essa posse afetiva da qual já se habituara ele a ser o exclusivo senhor (Vítor, p. 136). La ruptura de ese noivado de espectros (p. 140) ocurre cuando, durante una pelea, Ernesto insulta a su amigo, Ilamándolo "imbécil". El insulto provoca una fiebre de ira e indignación en Bruce, quien, en su delirio, comienza a imaginar a su antiguo amigo a las carcajadas,

5 Felix Pacheco ha definido el cuento "Sapo" como una "mixórdia hedionda" (A meridional, 28 de febrero de 1899, n. 1). Pero Rocha Pombo escribe: Leia o sapo quem quiser ver como se sobe e se desce na vida, e sobretudo como num homem se podem resumir todos os mistérios que envolvem o grande tema do mundo moral (Rocha Pombo, Gazeta da Tarde, 5 out 1895 [?]). 
burlándose de él (como el mismísimo "Emparedado" de Cruz e Sousa). Con la separación, Bruce, además de ser tomado por sentimientos ginofóbicos, comienza a mostrar signos de "atavismo", finalmente autodefiniéndose como miembro de un linaje de abyectos y condenados en proceso de degeneración y obliteração moral (p. 192), un desgraçado proscrito: O pai, aquele homem estranho, fora decerto um triste exilado do Céu; como possivelmente também o avô: Eles eram, quem sabe? uma família de eleitos (p. 172).

Despedido de la oficina en donde trabajaba, Bruce dirige todo su odio al mundo que lo rodea, al que imagina como un pantano poblado por seres negros o ennegrecidos, finalmente metamorfoseados en batracios: Os homens, de tão negros que Ihe ficavam, já Ihe pareciam verdes, caíam de quatro, e a terra se lhe afigurava, então, um pantanal imenso, estagnado e podre, coalhado de sapos, a coaxarem miseráveis e repugnantes (p. 170). Así, contra el ambiente hostil, el exiliado social solo puede repetir el mismo insulto ("sapo! sapo!"). Al mismo tiempo, en medio de las multitudes heterogéneas de las calles de Río de Janeiro, Bruce se siente libre de convenciones sociales, sucumbiendo a una vida licenciosa de juego y alcohol, hasta que finalmente se encuentra con un viejo conocido cuya "fisionomia" revela la figura del probable delincuente: Cabelos pretos, olhos pretos, meio mortos, bigode preto, olheiras extremamente inchadas, beiços grossos, moreno, fronte estreita, todo o ar de um personagem lombrosiano (p. 195). Sintiéndose cada vez más desorientado y degradado, el personaje encuentra consuelo solo en compañía de ese antiguo compañero que ahora se entregaba a los "vícios de Sodoma" convirtiéndose en um sibarita dos de pior espécie (p. 198). Con su nuevo compañero, su propia condición de marginado social y disidente sexual se hace evidente, lo que hace que Bruce comprenda, en retrospectiva, la naturaleza de su amistad y la razón de sus celos por Ernesto. Incapaz de escapar del poder simbólico de la opinión pública y de la ley, Bruce imagina la palabra injuriosa que había lanzado con anterioridad al mundo se volvía ahora contra sí mismo, y repetida en la voz fantasmagórica del padre: Filho, eu ainda te chamo assim para ter o direito de te amaldiçoar, como te amaldiçoo para sempre [...] Hoje, Bruce, tu és sapo! (p. 205). Finalmente, el insulto que lo persigue y lo atormenta se materializa en su identidad, y Bruce se metamorfosea gradualmente en un sapo, ya aquí encarnando la condición de poeta condenado y decadente: Começa então a coaxar. São notas tão tristes essas de seu estranho canto monótono... (p. 207).

Dividido entre la ideología patologizante de la antropología criminal de Lombroso, por un lado, y la fascinación del fin de siglo con el poeta maldito y decadente, por el otro, Nestor Vítor produjo en "Sapo" un extraordinario retrato de la abyección social-sexual en el Río de Janeiro finisecular. No sorprende que Cruz e Sousa viese allí reflejadas algunas de sus propias obsesiones. Según el ensayo dedicado al libro del amigo, todos los cuentos de Signos, da forma por que estão elaborados, trazem essa propriedade secreta e característica que têm os Eleitos de confundir e mistificar o convencionalismo oficial da Opinião ( $p$. 792). Pero mientras el narrador ( $y$, luego, el lector implícito) del relato de Nestor Vítor parece aun evitar la complicidad o la identificación completa con el personaje homosexual exiliado en el submundo de Río de Janeiro, Cruz e Sousa encuentra en Bruce una afinidad que, en última instancia, promete una comunidad constituida 
por todos los individuos estigmatizados por las convenciones sociales. Es decir, es como si la voz exiliada del "sapo" remitiese a una especie de coro disonante compuesto por:

[t]odos os desclassificados do destino, todos os vacilantes, todos os sem rumo, todos os sem objetivo certo, todos os silenciosos do orgulho nobre, todos os corações amargos e fracos, todos os dolentes e desolados do espírito, todas as vidas de meia luz e de meia sombra, todos os vencidos da Glória, todos os inacabados, todos os incompletos que aspiram um Ser, todos os que ondulam entre a Fé e a Dúvida, todos os incompreendidos, todos os irresolutos ou covardes morais [...] (Cruz e Sousa, p. 787).

En otras palabras, así como reinterpreta al negro que lleva la marca de Cam como el condenado-elegido, Cruz e Sousa lee, en el disidente sexual de Nestor Vítor, el estigma del condenado, que es también una señal de nobleza y superioridad. Mientras que el naturalismo patologizaba o criminalizaba al negro y al homosexual (así como a la mujer histérica), convirtiéndolo en objeto de estudio, el diálogo simbolista entre Cruz e Sousa y Néstor Vítor les otorga el estatus de sujeto que, aunque proscrito, inaugura una nueva voz que responde a las heridas perpetradas por las teorías científicas.

Traducción: Carlos G. Halaburda

\section{Obras citadas}

Bastide, Roger. "Cruz e Sousa e Baudelaire: estudo de literatura comparada". A poesia afro-brasileira. São Paulo: Mosaico, 1943.

Bosil, Alfredo. Literatura e resistência. São Paulo: Companhia das Letras, 2002. Brissette, Pascal. "Poète malheureux, poète maudit, malédiction littéraire". COnTEXTES [on-line], s.n., 12 de mayo de 2008. Disponible en : http:// contextes. revues.org/1392.

Buffon, George Louis Leclerc. Histoire Naturelle des quadrupeds-ovipares. t. 1. Paris: Rapet: 1819.

Cruz e Sousa, João da. Obra completa. Org. Andrade Muricy. Rio de Janeiro: Nova Aguilar, 2000.

Goldhill, Simon. Victorian Culture and Classical Antiquity: Art, Opera, Fiction and the Proclamation of Modernity. Princeton: Princeton U Press, 2011.

Le Clech, Martine e YVEN, François. Tristan Corbière. La métamorphose du crapaud. Plurin-lès-Morlaix, Bretagne d'hier, 1995.

Moisés, Massaud. A literatura brasileira: o simbolismo. São Paulo, Cultrix, 1967, v. 4.

Muricy, Andrade. Panorama do simbolismo brasileiro. São Paulo: Perspectiva, 1978, v. I.

Vigny, Alfred. Stello, S.I., 1832, cap. XII, s.p. Project Gutemberg, Disponible en: <http://www.gutenberg.org/cache/epub/9655/pg9655-images. html>.

Vítor, Nestor. "Sapo." In: Signos. Rio de Janeiro, 1897. 
